\title{
Assigning the phenotype of a natural regulatory T-cell to the human T-cell line, KARPAS-299
}

\author{
CARMEN WOLKE ${ }^{1}$, JANINE TADJE$^{1}$, ALICJA BUKOWSKA $^{1}$, MICHAEL TÄGER $^{3}$, UTE BANK $^{3}$, \\ ANNELORE ITTENSON ${ }^{2}$, SIEGFRIED ANSORGE ${ }^{3}$ and UWE LENDECKEL ${ }^{1}$ \\ Institutes of ${ }^{1}$ Experimental Internal Medicine, and ${ }^{2}$ Immunology, Otto-von-Guericke University; \\ ${ }^{3}$ IMTM, Leipziger Str. 44, D-39120 Magdeburg, Germany
}

Received August 19, 2005; Accepted October 3, 2005

\begin{abstract}
The human CD30-positive anaplastic large (T-) cell lymphoma cell line, KARPAS-299 (DSM ACC31), was established from blast cells in the peripheral blood from a case of non-Hodgkin lymphoma in 1988. We describe the mRNA and surface expression in KARPAS-299 cells of a panel of markers highly restricted to human natural regulatory T-cells and associated with their suppressive activity, including FOXP3, CD25, IL-10, TGF-31, CD62L, and LAG-3. Results obtained from co-culturing human peripheral blood leukocytes with KARPAS-299 cells assigned a suppressive phenotype to the latter ones. In conclusion, KARPAS-299 cells show characteristics typical of natural regulatory T-cells and, thus, represent a valuable model for studying regulatory T-cell function, which may also facilitate drug development aimed at the modulation of regulatory T-cell activity for the pharmacological therapy of, for example, autoimmune diseases.
\end{abstract}

\section{Introduction}

In the ten years since $\mathrm{CD} 4{ }^{+} \mathrm{CD} 25^{+}$regulatory $\mathrm{T}$-cells (Treg) and their pivotal role in regulating immune tolerance were first described (1), the underlying mechanisms of suppression and possible applications to control pathogenic T-cell responses in autoimmune, graft versus host, and inflammatory diseases has been the focus of enormous research efforts. As a consequence of this research, it is now clear that Treg represent a unique population of thymus-derived $\mathrm{CD}^{+} \mathrm{T}$-lymphocytes that constitutively expresses the $\alpha$-chain of the IL-2 receptor (CD25), CTL-associated antigen-4 (CTLA-4), and L-selectin (CD62L). The Treg population comprises 5-10\% of circulatory CD4+ T-cells and acts to powerfully suppress responder T-cells in vitro and in vivo (2-4).

Correspondence to: Dr Uwe Lendeckel, Institute of Experimental Internal Medicine, Otto-von-Guericke University, Leipziger Str. 44, D-39120 Magdeburg, Germany

E-mail: uwe.lendeckel@medizin.uni-magdeburg.de

Key words: T-cell line, autoimmune diseases
The mechanisms responsible for Treg-mediated suppression of the immune response remain to be elucidated fully. In particular, little is known about Treg-specific surface markers and related co-stimulatory pathways required for the acquaintance of full suppressive activity. CD62L, neuropilin-1, lymphocyte-activating gene-3 (LAG-3), and the Ki1-antigen (CD30) are among the surface molecules that have been assigned to the Treg phenotype (5-7). Treg are also unique in the expression at their cell surface of both latent and active transforming growth factor (TGF)- $\$ 1$ (8), a feature that is believed to facilitate contact-dependent inhibition of responder T-cells. However, the role of TGF- $\beta 1$ in the suppressive activity remains controversial, as is the role of CTLA-4 signalling (9). In vitro generation of Treg is achieved by activation in the presence of the immunosuppressive cytokines, TGF- $\beta 1$ and interleukin (IL)-10 (10). Previous studies imply that TGF- $\beta 1$-induced gene expression of FOXP3, a transcription factor that is believed to be exclusively expressed in $\mathrm{CD} 4{ }^{+} \mathrm{CD} 25^{+}$and $\mathrm{CD} 8{ }^{+} \mathrm{CD} 25^{+} \mathrm{T}$-cells, which correlates with their suppressive phenotype in humans and mice $(11,12)$, converted naive $\mathrm{CD} 4{ }^{+} \mathrm{CD} 25^{-}$T-cells into anergic/ suppressor cells upon T-cell receptor (TCR) activation (13). In both mice and humans, $\mathrm{CD} 4{ }^{+} \mathrm{CD} 25^{+}$cells have been shown to constitutively express high levels of TGF- $\beta 1$, and application of anti-TGF- $ß 1$ antibodies leads to a dose-dependent decrease in suppressive activity in humans and mice (8). However, tools to support the Treg function in vivo and in vitro remained elusive.

\section{Results and Discussion}

We show that the human T-cell lymphoma cell line, KARPAS299, exhibits a 'Treg-specific' mRNA and surface expression pattern. Furthermore, KARPAS-299 cells are capable of inhibiting the growth of co-cultured PHA/PMA-stimulated MNC.

The human cell line, KARPAS-299, was established from the peripheral blood of a 25-year-old man with T-cell nonHodgkin lymphoma by Fischer et al (14) in 1988 and is now classified as 'CD30+ anaplastic large cell lymphoma' (ALCL). It is known as CD25-positive. As the CD25 cell surface protein is also constitutively expressed on natural regulatory T-cells and is widely used to identify and enrich Treg, we investigated by RT-PCR the presence of this and other 'Treg-specific' 
Table I. Primers used for RT-PCR analyses.

\begin{tabular}{lll}
\hline Specific mRNA & \multicolumn{1}{c}{ Upstream primer ${\text { 5' } \rightarrow 3^{\prime}}^{\prime}$} & \multicolumn{1}{c}{ Downstream primer 5' $\rightarrow 3^{\prime}$} \\
\hline TGF- $\beta 1$ & CAGAAATACAGCAACAATTCCTGG & TTGCAGTGTGTTATCCGTGCTGTC \\
IL-10 & GCCTAACATGCTTCGAGATC & TGATGTCTGGGTCTTGGTTC \\
CD25 & GACGATGACCCGCCACAGATCCCA & CCTGGACGCACTGATAATAAACCA \\
Neuropilin-1 & CTTACATCTCCTGGTTATCC & TTCTGGGAACATTCAGGACC \\
CD62L & CACCTGCAACTGTGATGTGG & GAGCAGATGAAGGTACATGC \\
LAG-3 & CTCAGTTCCTGGGCTTGCTG & CTGGCTGATGCTGCCAAGTG \\
FOXP3 & TGTCAGTCAACTTCACCAAG & AGCTGGTGCATGAAATGTGG \\
mAAP/CD13 & GGTGGTGCACCTCAAGGG & GGAAGCATGTTGGACAGGG \\
DPIV/CD26 & GATGCTACAGCTGACAGTCGC & TGGTGACCATGTGACCCACTG \\
\hline
\end{tabular}

Table II. mRNA and surface expression of various human T-cell lines.

\begin{tabular}{|c|c|c|c|c|c|c|c|}
\hline & \multicolumn{2}{|c|}{ KARPAS-299 } & \multirow{2}{*}{$\begin{array}{c}\text { P12/Ichikawa } \\
\text { mRNA }\end{array}$} & \multirow{2}{*}{$\begin{array}{c}\text { Jurkat E6.1 } \\
\text { mRNA }\end{array}$} & \multirow{2}{*}{$\begin{array}{c}\text { H9 } \\
\text { mRNA }\end{array}$} & \multirow{2}{*}{$\begin{array}{l}\text { Molt-4 } \\
\text { mRNA }\end{array}$} & \multirow{2}{*}{$\begin{array}{l}\text { Treg } \\
\text { mRNA }\end{array}$} \\
\hline & mRNA & FACS & & & & & \\
\hline IL-2R/CD25 & +++ & $100 \%$ & - & - & $(+)$ & - & +++ \\
\hline FOXP3 & ++ & n.d. & - & - & - & - & +++ \\
\hline TGF- $ß 1$ & +++ & n.d. & +++ & ++ & +++ & + & +++ \\
\hline IL-10 & ++ & n.d. & + & $(+)$ & $(+)$ & - & ++ \\
\hline CD62L & ++ & $11-36 \%$ & +++ & ++ & +++ & - & +++ \\
\hline LAG-3/CD223 & ++ & n.d. & + & ++ & ++ & +++ & +++ \\
\hline Neuropilin-1 & ++ & n.d. & + & ++ & + & - & ++ \\
\hline mAAP/CD13 & ++ & $9-51 \%$ & + & + & + & + & +++ \\
\hline DPIV/CD26 & +++ & $100 \%$ & $(+)$ & - & $(+)$ & - & ++ \\
\hline
\end{tabular}

+++, strong expression; ++, moderate expression; +, low expression; (+), marginal expression; -, no expression; n.d., not determined. KARPAS-299 (DSM ACC31) and P12/Ichikawa (DSM ACC34) cells were purchased from the German Collection of Microorganisms and Cell Cultures (DSMZ, Braunschweig, Germany). H9 (ECACC No. 85050301), Jurkat E6.1 (88042803), and Molt-4 (85011413) were obtained from the European Collection of Cell Cultures (ECACC). Cells were grown in RPMI/10\% FCS at a maximum density of $0.5 \times 10^{6}$ cells $/ \mathrm{ml}$. Cytofluorimetric analyses were performed with a FACS Calibur (Becton-Dickinson, San Jose, CA) using polyclonal chicken anti-TGF- 31 (R\&D Systems, Minneapolis, MN), anti-CD13, anti-CD25 (clone 123-13, Becton-Dickinson), anti-CD26 (Becton-Dickinson), and antiCD62L (Coulter/Immunotech, Miami, FL). TRITC-rabbit anti-chicken IgG (Sigma, Deisenhofen, Germany) was used for TGF-ß1-staining and donkey-anti-rabbit PE-conjugate (Dianova, Hamburg, Germany) was used for all other unlabelled antibodies.

markers in KARPAS-299 cells in comparison to four other T-cell lines (Tables I and II).

CD25 appeared to be weakly expressed in H9-cells, but was completely absent in the other T-cell lines. TGF- 31 and IL-10, both being immunosuppressive cytokines typically produced by Treg and functionally linked with its suppressive activity, showed highest expression levels in KARPAS-299 cells. Molt-4 cells completely lacked TGF- 31 expression and only marginally expressed IL-10, whereas IL-10 was practically absent also from H9 or Jurkat E6.1 cells (Table II).

A $100 \%$ 'Treg-specific' marker has not yet been identified. The transcription factor, FOXP3, however, is regarded as rather selectively expressed by Treg (15). We show here that, among the various T-cell lines analysed, KARPAS-299 cells are unique in their expression of FOXP3. To further support this finding, which is suggestive of KARPAS-299 cells exhibiting a Treg phenotype, the expression of other recently proposed Treg-markers was studied. Huang et al (7) reported that surface-bound LAG-3 is required for proper Treg function, whereas another study (5) proposed neuropilin-1 as Treg surface marker. Fu et al (6) identified CD62L-positive Treg as more potent suppressors than the CD62L-negative fraction. Our results show that all of these three surface molecules are widely expressed among different T-cell lines. Thus, despite their clear association with the Treg phenotype, these markers on their own are not sufficient to define Treg.

Recently, we demonstrated the expression of membrane alanyl-aminopeptidase (mAAP) mRNA in human Treg of healthy volunteers. Among the various leukocyte and T-cell subsets analysed, Treg showed by far the highest mAAP mRNA levels. In accordance with this observation, KARPAS299 cells exhibit strong mAAP mRNA and surface (CD13) expression. The surface expression of CD13 appeared variable, depending on the proliferation state. Inhibitors of the enzymatic activities of both mAAP/CD13 and dipeptidyl peptidase IV (CD26) exhibit strong immunosuppressive activity which, at 


\begin{tabular}{|c|c|c|c|c|}
\hline & $\begin{array}{c}\text { MW } \\
(\mathrm{kDa})\end{array}$ & MNC- & Treg & $\begin{array}{c}\text { KARPAS- } \\
299\end{array}$ \\
\hline FOXP3 & $47.5 \rightarrow$ & & & \\
\hline TGF- $\beta 1$ & $12.5 \rightarrow$ & & & \\
\hline
\end{tabular}

Figure 1. Detection of FOXP3 and TGF- 11 in 2x106 KARPAS-299 cells by immunoblot analysis. Expression in KARPAS-299 cells was comparable to that of human Treg, whereas equal numbers of MNC depleted of Treg (MNC-) practically lacked FOXP3 and showed only weak TGF- 1 expression. Immunodetection of FOXP3 and TGF- 11 was performed as described (20) using the following antibodies: polyclonal rabbit anti-FOXP3 (ab10563, 1:500, abcam, Cambridge, UK), anti-rabbit-IgG-horseradish peroxidase (1:5000, Cell Signaling, Beverly, USA), polyclonal chicken anti-TGF-ß1 (1:500, R\&D Systems, Minneapolis, MN), rabbit anti-chicken-alkaline phosphatase (1:2000, R\&D).

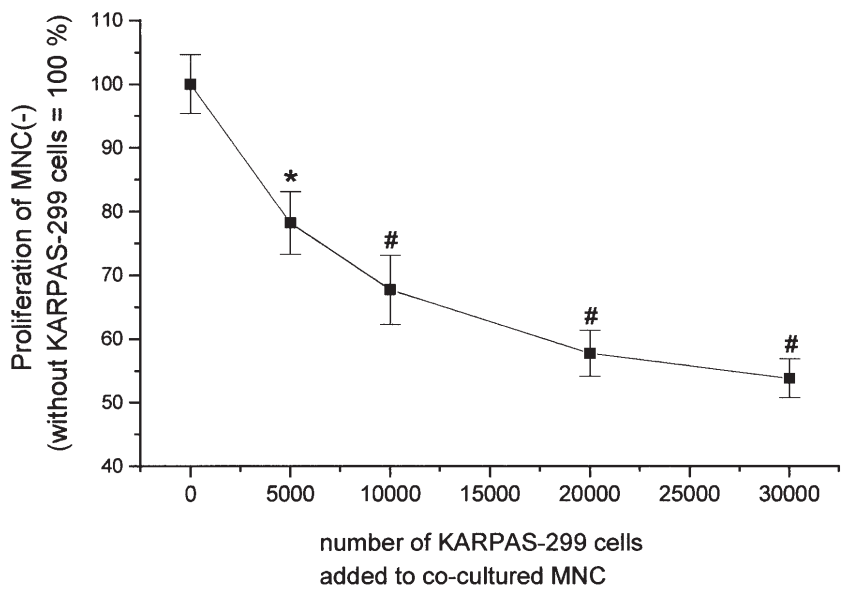

Figure 2. KARPAS-299 cells suppress the growth of co-cultured MNC depleted of Treg (MNC-). Peripheral blood mononuclear cells (MNC) were isolated from venous blood of healthy donors as described (21). Treg were positively selected from human MNC using CD25-Microbeads (Miltenyi Biotech, Bergisch-Gladbach, Germany). The MNC depleted of Treg were seeded in 96-well plates at 30000 cells/well/150 $\mu 1$ and co-cultured with different numbers of KARPAS-299 cells placed in $0.2 \mu \mathrm{m}$ Nunc tissue culture inserts. After $96 \mathrm{~h}$, the inserts were removed and proliferation of the MNC was measured by using the Cell Proliferation kit (Promega, Mannheim, Germany). Mean of 3 experiments $\pm \mathrm{SD},{ }^{\#} \mathrm{P}<0.021 ;{ }^{*} \mathrm{P}<0.035$.

least partly, is due to an induction of TGF- $\$ 1$ production and release (16-19). As both ectopeptidases appear to be strongly expressed in KARPAS-299 cells and human Treg, we conclude that mAAP and DPIV expression is another, although not exclusive, feature of human natural Treg.

Collectively, the available data imply that the Treg phenotype is established by the simultaneous expression of a panel of surface markers, which alone are not exclusive for these cells. Essential prerequisites for a functionally active Treg are the presence of FOXP3, TGF-31, IL-10, LAG-3, CD25, CD62L, and, probably, CD13. All of these markers appear highly expressed in KARPAS-299 cells, which are thereby clearly distinguished from other T-cell lines. Taking into account the special role of FOXP 3 and TGF- $\beta 1$ for the suppressive activity of Treg, the expression of both Treg markers was also assessed at the protein level by immunoblot analysis. As shown in Fig. 1, TGF- 31 and FOXP3 protein expression in KARPAS-299 cells was as high as in purified human Treg, whereas equal numbers of MNC that had been depleted of Treg contained no FOXP3 and traces of TGF- 31 only. To verify that also the immunosuppressive cytokine, IL-10, is expressed and secreted as a mature protein, IL-10 contents in the supernatant of KARPAS-299 cells were determined 24 and $48 \mathrm{~h}$ after seeding by a commercially available ELISA (R\&D Systems). Thereby, we detected significant amounts ( $24 \mathrm{~h}, 49.8 \mathrm{pg} / \mathrm{ml} ; 48 \mathrm{~h}, 136 \mathrm{pg} / \mathrm{ml})$ of IL-10 in the supernatant of KARPAS-299 cells.

Both the mRNA and protein expression pattern of KARPAS-299 cells fully concur with a regulatory T-cell phenotype. In contrast, all other investigated T-cell lines do not show the complete characteristics of Treg.

We then analysed whether KARPAS-299 cells also exhibit the functional, suppressive properties of Treg. In co-culture experiments, KARPAS-299 cells were proven capable of suppressing the proliferation of MNC, previously depleted from $\mathrm{CD} 4{ }^{+} \mathrm{CD} 25^{+}$cells, in a dose-dependent manner (Fig. 2). These results are in full accordance with data obtained by using human Treg in analogous experiments (data not shown).

In summary, the data presented here imply that the human T-cell lymphoma cell line, KARPAS-299, represents a functionally active regulatory $\mathrm{T}$ cell. Considering the important role that $\mathrm{CD} 4^{+} \mathrm{CD} 25^{+} \mathrm{T}$-cells play in maintaining immune-tolerance, there is a great demand for studies on the identification of regulatory mechanisms and possible ways to attenuate Treg function. Using KARPAS-299 cells as a model of Treg function might greatly facilitate such studies.

\section{Acknowledgements}

We thank Katja Mook and Astrid Giese for their excellent technical assistance. This work was supported by grants from the Deutsche Forschungsgemeinschaft (Le900/4-1), the Bundesministerium für Bildung und Forschung (Innovative Regionale Wachstumskerne, PharmaMD, WKD02C), and the Kultusministerium Sachsen-Anhalt, Germany (PharmaMD, 3536B/0903M).

\section{References}

1. Sakaguchi S, Sakaguchi N, Asano M, Itoh M and Toda M: Immunologic self-tolerance maintained by activated $\mathrm{T}$ cells expressing IL-2 receptor alpha-chains (CD25). Breakdown of a single mechanism of self-tolerance causes various autoimmune diseases. J Immunol 155: 1151-1164, 1995.

2. Dieckmann D, Plottner H, Berchtold S, Berger T and Schuler G: Ex vivo isolation and characterization of CD4(+)CD25(+) T cells with regulatory properties from human blood. J Exp Med 193: 1303-1310, 2001.

3. Shevach EM: Suppressor T cells: rebirth, function and homeostasis. Curr Biol 10: R572-R575, 2000.

4. Shevach EM: Certified professionals: CD4(+)CD25(+) suppressor T cells. J Exp Med 193: F41-F46, 2001.

5. Bruder D, Probst-Kepper M, Westendorf AM, Geffers R, Beissert S, Loser K, von Boehmer H, Buer J and Hansen W: Neuropilin-1: a surface marker of regulatory T cells. Eur J Immunol 34: 623-630, 2004.

6. Fu S, Yopp AC, Mao X, Chen D, Zhang N, Mao M, Ding Y and Bromberg JS: CD $4{ }^{+} \mathrm{CD} 25^{+} \mathrm{CD} 62^{+}$T-regulatory cell subset has optimal suppressive and proliferative potential. Am J Transplant 4: 65-78, 2004.

7. Huang CT, Workman CJ, Flies D, Pan X, Marson AL, Zhou G, Hipkiss EL, Ravi S, Kowalski J, Levitsky HI, Powell JD, Pardoll DM, Drake CG and Vignali DA: Role of LAG-3 in regulatory T cells. Immunity 21: 503-513, 2004. 
8. Nakamura K, Kitani A and Strober W: Cell contact-dependent immunosuppression by $\mathrm{CD} 4(+) \mathrm{CD} 25(+)$ regulatory $\mathrm{T}$ cells is mediated by cell surface-bound transforming growth factor beta. J Exp Med 194: 629-644, 2001.

9. Shevach EM: $\mathrm{CD}^{+} \mathrm{CD} 25^{+}$suppressor $\mathrm{T}$ cells: more questions than answers. Nat Rev Immunol 2: 389-400, 2002.

10. Jiang S, Camara N, Lombardi G and Lechler RI: Induction of allopeptide-specific human $\mathrm{CD} 4{ }^{+} \mathrm{CD} 25^{+}$regulatory $\mathrm{T}$ cells ex vivo. Blood 102: 2180-2186, 2003.

11. Itoh M, Takahashi T, Sakaguchi N, Kuniyasu Y, Shimizu J, Otsuka F and Sakaguchi S: Thymus and autoimmunity: production of $\mathrm{CD} 25^{+} \mathrm{CD} 4^{+}$naturally anergic and suppressive $\mathrm{T}$ cells as a key function of the thymus in maintaining immunologic self-tolerance. J Immunol 162: 5317-5326, 1999.

12. Thornton AM and Shevach EM: $\mathrm{CD} 4^{+} \mathrm{CD} 25^{+}$immunoregulatory $\mathrm{T}$ cells suppress polyclonal $\mathrm{T}$ cell activation in vitro by inhibiting interleukin 2 production. J Exp Med 188: 287-296, 1998.

13. Chen W, Jin W, Hardegen N, Lei KJ, Li L, Marinos N, McGrady G and Wahl SM: Conversion of peripheral CD4+CD25naive $\mathrm{T}$ cells to $\mathrm{CD} 4{ }^{+} \mathrm{CD} 25^{+}$regulatory $\mathrm{T}$ cells by TGF-beta induction of transcription factor FOXP3. J Exp Med 198: 1875-1886, 2003.

14. Fischer P, Nacheva E, Mason DY, Sherrington PD, Hoyle C, Hayhoe FG and Karpas A: A Ki-1 (CD30)-positive human cell line (Karpas 299) established from a high-grade non-Hodgkin's lymphoma, showing a $2 ; 5$ translocation and rearrangement of the T-cell receptor beta-chain gene. Blood 72: 234-240, 1988.
15. Fontenot JD, Gavin MA and Rudensky AY: Foxp3 programs the development and function of $\mathrm{CD} 4{ }^{+} \mathrm{CD} 25^{+}$regulatory $\mathrm{T}$ cells. Nat Immunol 4: 330-336, 2003.

16. Kähne T, Lendeckel U, Wrenger S, Neubert K, Ansorge S and Reinhold D: Dipeptidyl peptidase IV: a cell surface peptidase involved in regulating T cell growth (review). Int J Mol Med 4: 3-15, 1999.

17. Lendeckel U, Arndt M, Frank K, Wex T and Ansorge S: Role of alanyl aminopeptidase in growth and function of human $\mathrm{T}$ cells (review). Int J Mol Med 4: 17-27, 1999.

18. Reinhold D, Kähne T, Steinbrecher A, Wrenger S, Neubert K, Ansorge S and Brocke S: The role of dipeptidyl peptidase IV (DP IV) enzymatic activity in T cell activation and autoimmunity. Biol Chem 383: 1133-1138, 2004.

19. Bukowska A, Tadje J, Arndt M, Wolke C, Kähne T, Bartsch J, Faust J, Neubert K, Hashimoto Y and Lendeckel U: Transcriptional regulation of cytosol and membrane alanyl-aminopeptidase in human T cell subsets. Biol Chem 384: 657-665, 2003.

20. Thielitz A, Bukowska A, Wolke C, Vetter R, Lendeckel U, Wrenger S, Hashimoto Y, Ansorge S, Gollnick H and Reinhold D: Identification of extra- and intracellular alanyl aminopeptidases as new targets to modulate keratinocyte growth and differentiation. Biochem Biophys Res Commun 321: 795-801, 2004.

21. Ansorge S, Reinhold D and Lendeckel U: Propolis and some of its constituents down-regulate DNA synthesis and inflammatory cytokine production but induce TGF-beta1 production of human immune cells. Z Naturforsch 58: 580-589, 2003. 